\title{
Conversando de biología sintética en el gimnasio
}

\author{
Gerardo Ruíz Amores
}

\begin{abstract}
Resumen
La biotecnología moderna, con el uso de herramientas desarrolladas en la ingeniería genética y la biología sintética, produce bienes biológicos funcionales en salud, alimentación, industria, medicina, entre otros. Algunos países de Europa, Asia, Norteamérica y Sudamérica son líderes en este campo, en donde el interés en el análisis de riesgos, así como en el registro de patentes de las tecnologías generadas fortalecen sus aplicaciones y redituabilidad. En México, se invierte en investigación; sin embargo, esperamos a que la tecnología generada por otros países llegue pronto. En este contexto, dos personas hacen amistad al conocerse en el gimnasio. Mario, un abogado sociable, y Frank, una persona un poco inusual. Frank responde las inquietudes de Mario referentes a qué y cómo se hace biología sintética. Finalmente, estos personajes coinciden en que México tiene espíritu emprendedor, creatividad y una economía en desarrollo, y que la competitividad se conseguirá por la apropiada administración de recursos, la inclusión de la sociedad en la ciencia, el impartir prácticas bioéticas desde temprano en la educación y mejores políticas.
\end{abstract}

Palabras clave: biología sintética, biotecnología, ingeniería genética, material genético, bioética.

\section{TALKING ABOUT SYNTHETIC BIOLOGY AT THE GYM}

\begin{abstract}
Biotechnology, genetic engineering and synthetic biology produce goods in health, food, industry, and even patents. Countries in Europe, Asia, North, and South America are leaders in those fields. Mexico invests in research; however, we also hope that the technology generated by other countries will arrive soon. In this context, two people become friends at the gym. Mario, a sociable lawyer, and Frank, a slightly unusual person. Frank answers Mario's concerns regarding what is and how synthetic biology is done. Finally, they agree that Mexico has an entrepreneurial spirit, creativity and an economy in development; thus, competitiveness will be achieved by the appropriate administration of resources, inclusion of society in science, imparting bioethical practices from an early age in education, and better policies.
\end{abstract}

Keywords: synthetic biology, biotechnology, genetic engineering, genetic material, bioethics.

Recepción: 27/09/2020. Aprobación: 05/03/2021. Dol: http://doi.org/10.22201/cuaieed.16076079e.2021.22.3.9 


\section{Gerardo Ruíz Amores}

amoresgr@gmail.com

orcid.org/0000-0001-7905-6741

Actualmente es investigador independiente y miembro del Sistema Nacional de Investigadores. Tiene experiencia postdoctoral en biotecnología ambiental por El Colegio de la Frontera Sur, México. Es doctor en ciencias en biología molecular y celular, egresado de la Universidad de São Paulo en Ribeirão Preto, Brasil. Maestro en ciencias bioquímicas por el Instituto de Biotecnología de la Universidad Nacional Autónoma de México e ingeniero biotecnólogo por la Universidad Autónoma de Chiapas. Realizó dos estancias de investigación en el Instituto de Bioingeniería de la Universidad de Edimburgo en Escocia. También ha trabajado en el Centro Regional de Investigación en Salud Publica del Instituto Nacional de Salud Pública y se ha desempeñado como profesor de asignatura de la Universidad Politécnica de Tapachula, en las ingenierías en Agroindustrial, Tecnología Ambiental y Energía. Ha publicado en revistas nacionales de divulgación e internacionales especializadas. Su interés es la biotecnología ambiental, aplicando principios de biología sintética. 


\section{Rompiendo el hielo en el gimnasio}

Soy Mario, tengo casi cuarenta años. A esta edad el ejercicio es necesario. Por ello, voy al gimnasio, el cual, también resulta ser un lugar para socializar y conocer personas (ver imagen 1). Un día conocí a Frank, de apariencia reservada, excéntrico y con un toque de distraído.

—¿En qué trabajas? -le pregunté. respondió.

- Soy biólogo molecular, pero me especializo en biología sintética -

—_Ah ya sé! Como "un policía" de las series que identifican al culpable en la escena del crimen mediante el material genético — le dije.

—Ándale, puedo trabajar en algo así, pero en realidad la biología sintética se encarga del diseño o rediseño racional, usando, caracterizando y reutilizando partes moleculares en sistemas biológicos para proveerlos con una función mejorada o nueva para diversas aplicaciones (Tan et al., 2021). Esto es, explota la re-programación celular para obtener algún determinado bien —explicó Frank.

Los dos hicimos una cara de meme de wTF. Entonces, mientras pensaba que quizá eso explicaba su apariencia, se me salió un:

_ ¡Oye, espérate! ¿De qué estamos hablando?

Imagen 1. Conversando de biología sintética en el gimnasio. Imagen compuesta a partir de Needpix, s.f.b y Thadius856 y Parutakupiu, 2008

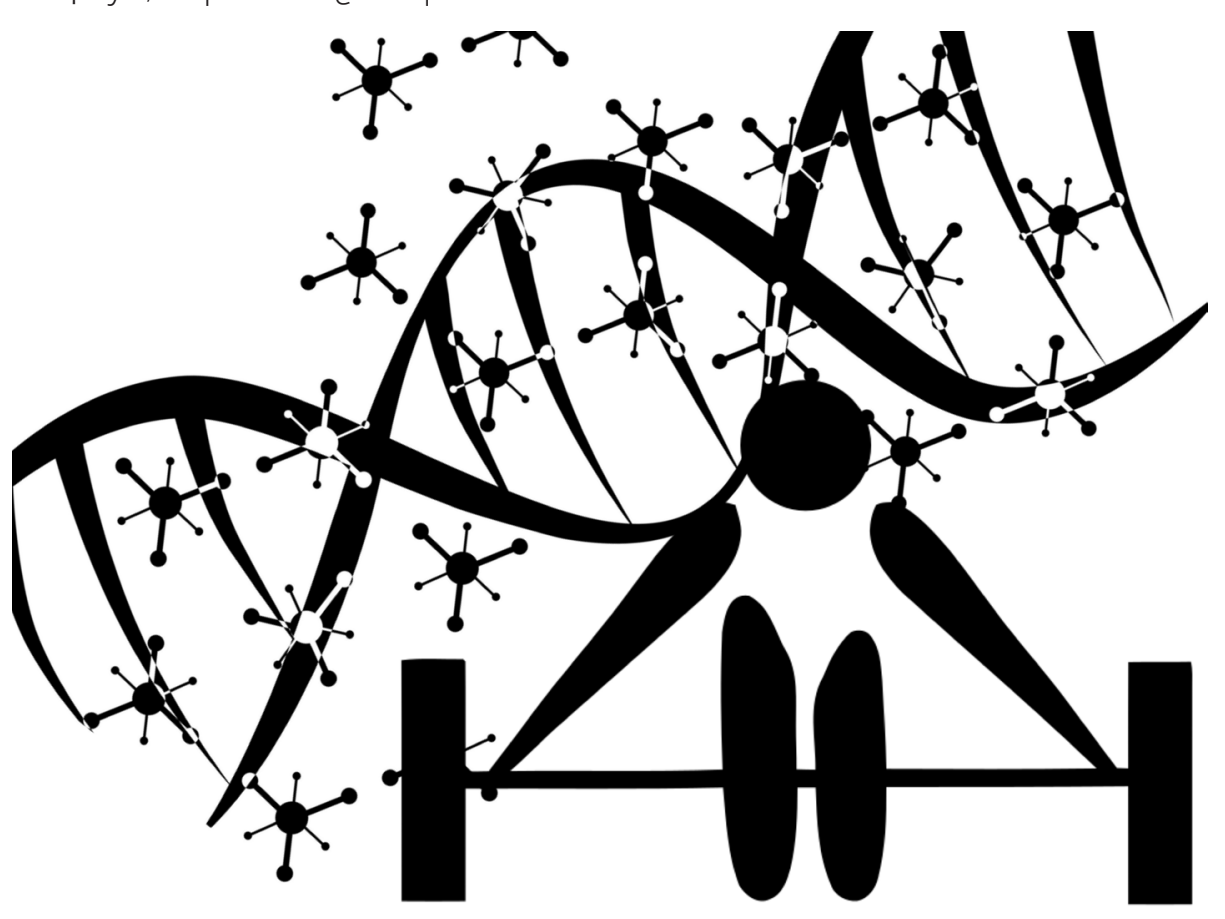


- Hablamos de biología, Mario, desde el desarrollo de una semilla de frijol a planta, hasta cosas como clonación de la oveja Dolly o maíz transgénico. ¿Has escuchado de esto, Mario?

-iSí! —exclamé-. La oveja clonada de Edimburgo, que después de esto se hicieron mas populares las películas de ciencia ficción, como aquella del goberneitor, del Sr. Schwarzenegger en la película de El sexto día.

-Muy bien, Mario - me dijo- Ahora, veamos los tres ejemplos anteriores. Porque en ninguno estamos hablando de biología sintética.

—CCómo así, Frank? ¿A qué te refieres? — pregunté, confundido.

-Mira, Mario, el experimento del frijol explica el desarrollo de un organismo, no de un humano, pero sí de una planta, un fenómeno base de la biología. Interesantemente, esta manipulación de vida en un frasco de vidrio, que podemos mantener viva al pasarla a una maceta o tirarla cuando queramos, es un experimento clásico de primarias. En las cuales, hasta donde a mí me tocó, nunca me explicaron acerca de la delicadeza de manejar los procesos vivos en frascos, llamados experimentos in vitro.

»Quiero decir, desde pequeños nos enseñan la importancia del estudio de la vida, pero poco nos hacen reflexionar sobre las atenciones que se deben de tener en el manejo de las cosas vivas, así como en lo pertinente que podría ser el desechar una planta a la basura. Ni siquiera nos dan una definición de bioética, tal como: "es la disciplina que estudia las dimensiones de la moral, las decisiones, la conducta, las políticas de las ciencias de la vida y del cuidado de la salud" (OmañaCovarrubias et al., 2021). Digo, finalmente es algo que quizá debería estar en los libros de texto para inculcarlo desde niños y llevarlo a la práctica continua.

Entonces, mientras Frank tomaba aire pensé: “iCaramba con Frank! Nunca creí que a alguien le afectara tanto desperdiciar una planta de frijol". Él, simplemente continuó:

-El segundo es un ejemplo biotecnológico de los 90, en el que se tomó el material genético de una oveja y se puso en una "célula vacía de material genético" de otra, originando una oveja idéntica a la primera.

-Oye, Frank, cuéntame con calma o me quedo con la idea de la película -intervine riendo.

- Tienes razón, Mario. De entrada, biotecnología es el uso de un organismo o cualquiera de sus partes para producir un determinado bien (Crowe, 2021). Por ejemplo, cuando un microorganismo es usado para hacer cerveza, vino o queso. En la oveja usaron únicamente una parte, el material genético. Imagina que extraemos el material genético de tu cabello y lo introducimos en un óvulo sin él. El bebé producto de esto sería idéntico a ti, incluso con las mismas enfermedades, en caso de que las tuvieras. 

emocionado.

_ ¡Claro, Frank! Eso es como el ejemplo del maíz transgénico —interrumpí

-Ese es el punto Mario, ese es un tipo de biotecnología en donde se usan herramientas de la ingeniería genética. En ese caso, toman el gen de un hongo capaz de matar al gusano que come maíz y lo "introducen" en el maíz para hacerlo resistente a la plaga, eso es biotecnología. Pero esta aplicación no sería posible sin la ingeniería genética. De esta manera, ingeniería genética se refiere a el uso de tecnología molecular para la edición del genoma de un organismo $(\mathrm{NIH}, 2021)$.

- ¡Ah, ya entendí Frank! Por ejemplo, el desarrollo de vacunas como las que se están aplicando para prevenir contraer covid-19 es biotecnología. E ingeniería genética es como lo de la noticia que salió de un científico asiático que terminó en la cárcel tras modificar embriones para tratar de prevenir la enfermedad del SIDA (ver imagen 2).

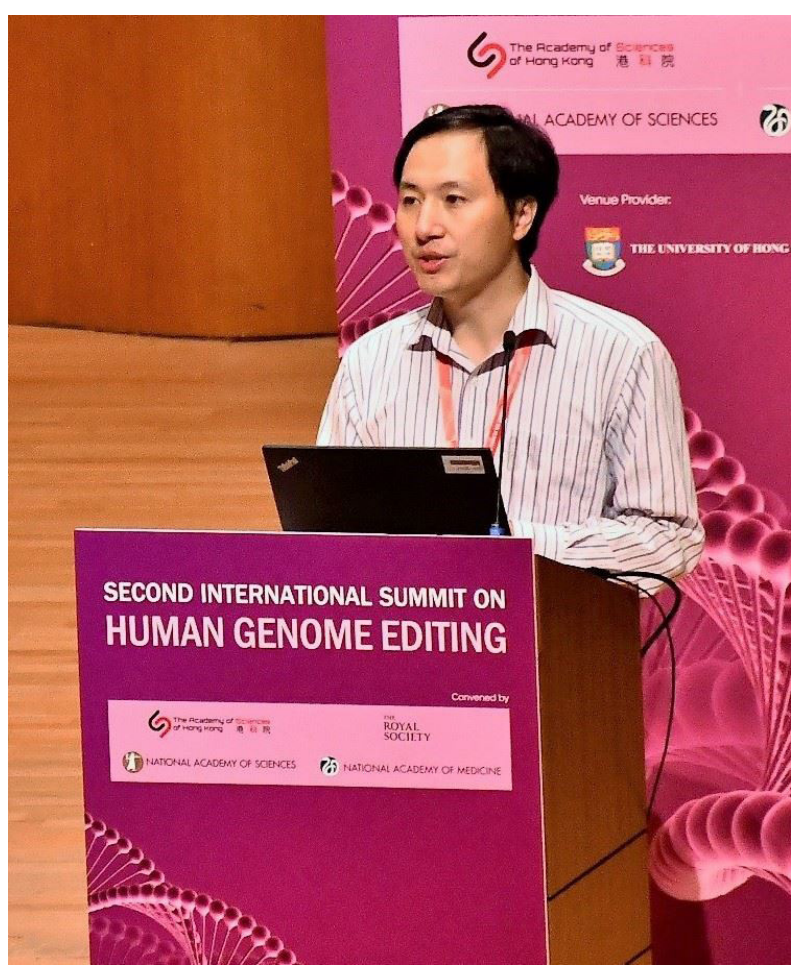

Imagen 2. He Jiankui, científico chino que editó genéticamente embriones que se implantaron y nacieron, obtiene tres años de prisión (Sui-Lee Wee, 2019).
- jEfectivamente, Mario! He Jiankui modificó un gen en embriones, de tal manera que, se piensa, pudiera proporcionar resistencia al HIv. Asimismo, logró, sin que los médicos lo supieran, implantarlos. Recibió varias críticas, por el uso inadecuado de la tecnología de edición de genoma, porque hay otras formas más efectivas de prevenir la transmisión de HIV (Normile, 2019). Como puedes ver, es sumamente necesario una educación temprana en la ciencia respecto a bioética, para poder entender, pero principalmente para emitir una opinión con conocimiento de si lo realizado por el científico es apropiado o no y si debía de ir a la cárcel. De cualquier forma, esos son solo ejemplos, pero creo que ya quedo más clara la diferencia entre ingeniería genética y biotecnología.

—Así es, Frank. Un gusto conocerte, luego le seguimos — dije, mientras guardaba mis cosas-. ¡Me tengo que ir! 


\section{Conociendo la biología sintética}

Llegando a la casa recordé que Frank nunca me dijo que era la biología sintética. Entonces pensé que debido a la forma en que me despedí, él habría pensado que me aburrí o que no me importaba lo qué hace. Entonces, al otro día en el gym, lo busqué para continuar hablando.

— ¿Qué pasó Frank? — hice un gesto con la mano-. Me tuve que ir rápido, ya que tenía pendientes, pero me di cuenta de que no me dijiste que hace la biología sintética. ¡Cuéntame!

—iSeguro! Primero te platicaré los posibles alcances — dijo, entusiasmado-. Imagina que pudiéramos introducir en un humano con diabetes una bacteria que produzca insulina, de una manera racional y lógica, a través de percibir las necesidades del paciente evitando así las inyecciones diarias de ese producto. Otro ejemplo, podría ser limpiar suelos o aguas contaminadas con diferentes compuestos como petróleo, mercurio y otras substancias. Aquí, se le puede dotar a un organismo con la capacidad de percibir el tipo de contaminante y en función de ello ajustar su metabolismo para poder "comer" el contaminante presente, y en caso de que un nuevo contaminante apareciera, el organismo podría percibir ese cambio y reestructurar su metabolismo para aprovechar ese nuevo contaminante. De esta forma, con un único organismo podríamos tratar diferentes contaminantes, reduciendo costos en el campo y aumentando la producción para obtener mas insumos.

_ ¡Caramba, Frank! Parece un nivel más especializado.

- En realidad, Mario, es una mezcla de diferentes áreas y campos de las ciencias y que sin duda se necesita fortalecer en México. Es una mezcla de biología, química, ciencias de la computación e ingeniería. Esto es interesante, porque si bien las tres primeras son bastante amplias, me gustaría comentarte particularmente la parte de ingeniería. Cuando decimos ingeniería, ¿a qué nos referimos, Mario?

- Mira Frank, puedo decirte que ingeniería es el diseño y construcción de estructuras, motores, máquinas.

— iExacto, Mario! Diseñar y construir de manera racional. En este caso es en organismos y lo que se construye son funciones biológicas y, efectivamente, se usan como máquinas para obtener la función deseada (Amores et al., 2016). Ahora bien, ¿cómo se construyen o rediseñan estas funciones biológicas? ¡Eso es lo bonito! Pero te cuento otro día, ¿qué te parece Mario?

- Mira Frank, mejor vamos a tomarnos unas cervezas para hablar de eso, por que la verdad está interesante y ya ni hago ejercicio. ¿Qué opinas?

- ¡Ya está, Mario! 


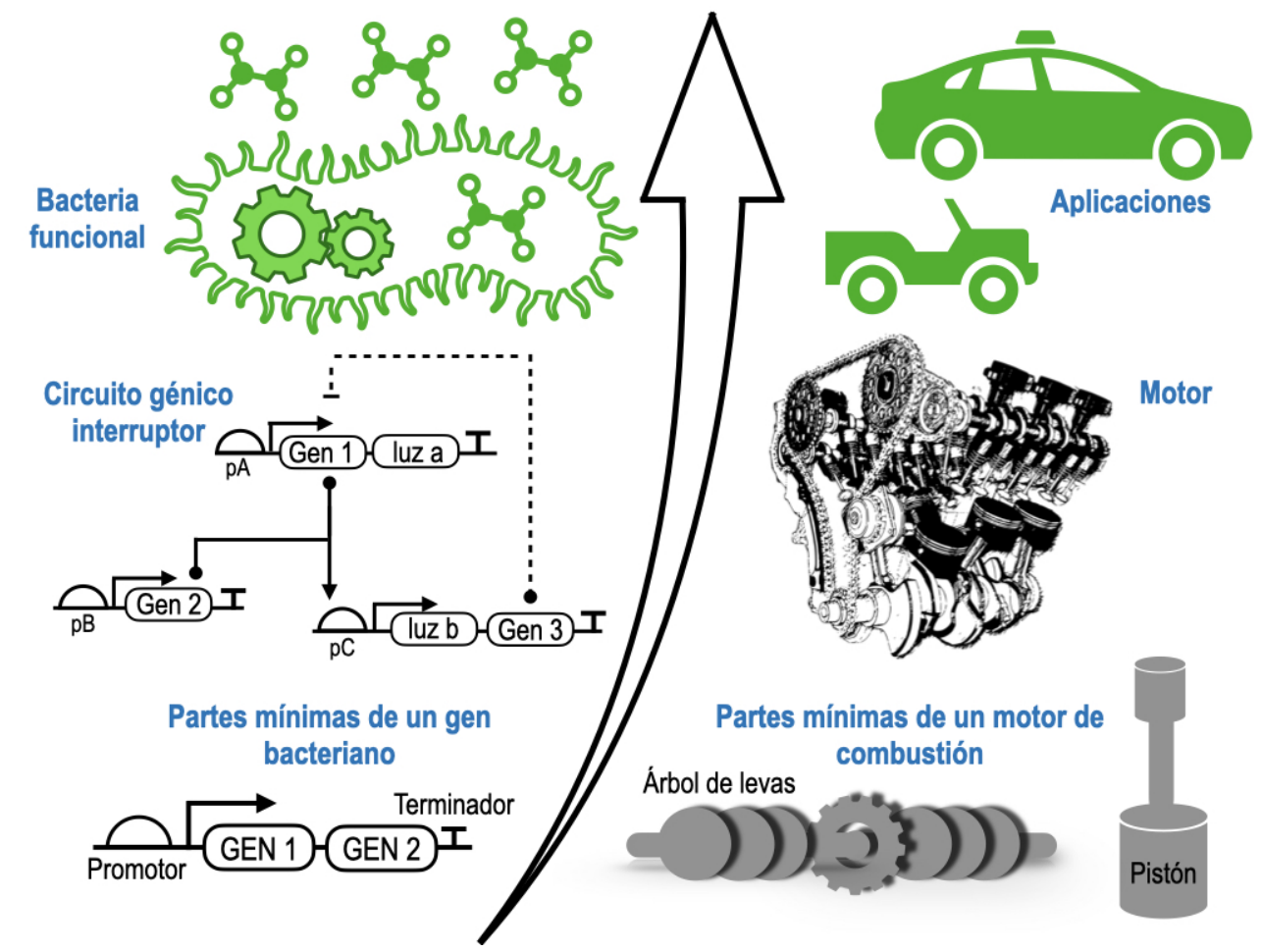

\section{Reflexionando en el restaurante}

Días después en el restaurante, pedimos los alimentos y cervezas. $Y$, ya que estoy por comprarme un automóvil le pregunté a Frank:

- ¿Qué carro comprarías? Estoy entre el sedan de la marca japonesa o de la alemana.

-Bueno, Mario, sí buscas rendimiento en carretera y dado que la diferencia de precio entre los dos es mínima, pienso que el más caro propone mejor rendimiento y quizá sea mejor.

- Gracias, Frank. Por cierto, hablando de carros. ¿Qué onda

Imagen 3. Niveles de ingeniería en biología sintética y su analogía con motores de combustión. a. De abajo hacia arriba se describe una pieza mínima de ingeniería genética bacteriana. Abajo: un promotor promueve activación del gen-secuencia de ácidos nucleicos con función (ej. luz). Un terminador es la señal de término de activación. En medio: ensamble de interruptores formando un circuito genético de comunicación. La activación del gen 1 y 2 activa el gen 3 , éste inhibe todo el circuito, generando oscilaciones. Arriba: la ingeniería de circuitos genera un organismo funcional bacteriano para la producción de una nueva molécula. b. De abajo hacia arriba se describen algunas piezas para construir un motor, en medio, el motor, y arriba, la aplicación de éste. Elaboración propia con contribución de Needpix, s.f.a. con las máquinas o motores biológicos? Te pregunto porque estoy queriendo entender bien qué es eso, para entrarle como abogado a lo de la bioética.

_ ¡Órale, Mario, suena una excelente idea! Porque justamente las piezas genéticas que se crean pueden ser patentadas.

— ¿A qué te refieres con piezas genéticas? —-pregunté.

- Por ejemplo, la movilidad del carro depende del motor, que tiene diferentes piezas. Y para que funcione de la forma que esperas, se debe conocer el desempeño de cada una de ellas. En palabras simples, tanto un sedan como un auto de carreras tienen pistones. Pero sus características son diferentes y, por tanto, su desempeño. Por eso es que no todos hacen carros de carreras, ¿cierto?

»Entonces, las funciones biológicas de organismos como, por ejemplo, la transformación de nutrientes, movilidad o respiración, dependen de genes. Éstos tienen segmentos con funciones particulares que les permite conectarse entre ellos como si fueran circuitos eléctricos o partes de un motor. Un "motor simple", en términos de genes, se llama interruptor. Es una comunicación que, como su nombre lo indica, la actividad de una pieza hace que la otra pieza se encienda. De manera interesante, se genera una señal de apagado a la primera pieza y se tiene como resultado algo así como un foco que se enciende y apaga. $Y$, ¿esto de qué sirve? Pues es simple, si conectas varios interruptores tienes funciones más complejas como una oscilación (ver imagen 3). Y, ¿qué es una oscilación en biología? Bueno, simplemente respira o siente tu palpitar. jY ahí lo 
tienes! Pero para terminar con la idea, un ensamble racional de piezas genéticas permite armar un sistema o circuito genético, que permite dotar al organismo con una función rediseñada o que no tenía (NIH, 2019).

_ ¡Mira nada más, Frank! Ahora entiendo. Es evidente que, si se "crea" una pieza genética apropiada para alguna función particular, tiene que ser patentada. Pero, por lo que he entendido y debido a los alcances y tecnologías que se emplean en el campo de la genética, es un campo de investigación que está bajo controversias, ¿no? Los aspectos sociales, éticos, bioéticos y legales son delicados.

GOBIERNO DE MÉXICO CONACYT

Con los ventiladores Ehécatl 4Ty Gätsi del Conacyt nace una industria nacional para salvar vidas

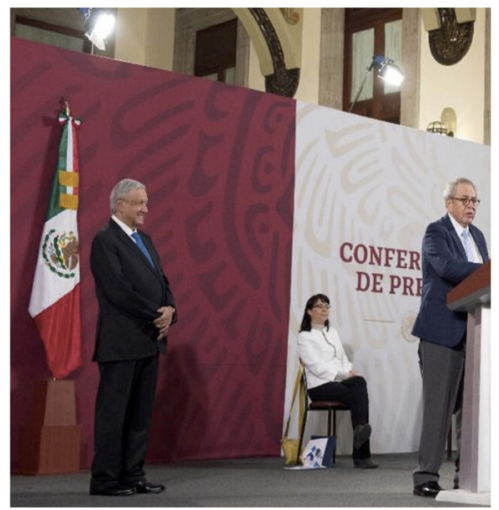

Imagen 4. Con los ventiladores Ehécatl 4T y Gätsi del CONACYT nace una industria nacional para salvar vidas (imagen adaptada de CONACYT, 2020).
-Así es, Mario. Lo que es interesante es que en lugares como Europa, Asia, América del Norte o del Sur, han visto una gran utilidad social en este campo. Entonces, los productos obtenidos son considerados como "un valor" con extensas aplicaciones y, por tanto, existe una inversión continua de diversos sectores, lo que resulta en patentes (Shapira et al., 2017). Lo más interesante es que las universidades en estos lugares son los responsables de entre 20 y $50 \%$ de la producción de las patentes con dinero propio o financiado, y el resto es de empresas privadas (Ribeiro y Shapira, 2020).

"¿Qué quiero decir? En México, hablar de organismos dotados con capacidades biológicas mejoradas o nuevas para resolver necesidades humanas parece un tabú. Sin embargo, cuando oímos que Rusia generó una nueva vacuna, o que Eu generó un neumático con plástico hecho por bacterias, lo que pensamos es que qué bueno que lo hicieron. Ojalá esa tecnología segura y limpia llegue aquí pronto, para curarnos o hacer un ambiente más sano. Entonces, una educación apropiada de bioética y ética en nuestra idiosincrasia, acompañada por el enorme talento de científicos mexicanos y la inmersión de la sociedad para exigir resultados, son necesarios para quitar el condicionamiento existente al desarrollo científico.

»En pocas palabras, considero que una dirección conjunta de los responsables de las tomas de decisiones relacionadas con el beneficio para los ciudadanos permitiría tener una expansión de la ciencia en México y llevarnos al primer mundo. Tal como lo acontecido a inicios de la pandemia, cuando el poder ejecutivo, el Consejo Nacional de Ciencia y Tecnología, y el ingenio de científicos mexicanos se coordinaron para construir en corto tiempo respiradores que permitieron salvar vidas (ver imagen 4), atendiendo así las necesidades que la nación estaba exigiendo. Entonces, te digo algo que hemos oído, pero difícilmente practicamos: tenemos que jalar juntos, pero para el mismo lugar, no en direcciones diferentes. 
- Caramba Frank, evidentemente es un tema complejo. Concuerdo con que debemos dejar de buscar esperanza en otros países e invertir más en la capacidad del personal mexicano. Pero debo mencionar que se debe tener una mejor educación para entender hasta dónde puede ser apropiada una tecnología. Mejor, vamos a terminarnos estas cervezas y pedir más biotecnología para terminar la comida. ¿Qué opinas, Frank?

— Hecho Mario, pidamos esta IPA —indicó una cerveza del menú-. ¡Seguro ha de estar buena! ¡Salud!

\section{Referencias}

* Amores, G. R., Guazzaroni, M. E., Arruda, L. M., y Silva-Rocha, R. (2016). Recent Progress on Systems and Synthetic Biology Approaches to Engineer Fungi As Microbial Cell Factories. Current genomics, 17(2), 85-98. https://doi.org/10.2174/13 89202917666151116212255

* Conacrt. (2020, 14 de julio). \#Comunicado | Con los ventiladores Ehécatl 4T y Gätsi del Conacyt nace una industria nacional para salvar vidas 40 https://bit. ly/38XI0zt [imagen] [actualización de estado]. Facebook. https://www.facebook. com/ConacytMX/posts/3298633700229109/

* Crowe, N. (2021) The Historiography of Biotechnology. En M. R. Dietrich, M.E. Borrello y O. Harman O. (Eds), Handbook of the Historiography of Biology (pp. 217241). Springer, Cham. https://doi.org/10.1007/978-3-319-90119-0_13

* National Human Genome Research Institute (NIH). (2019, 14 de agosto). Synthetic Biology. https://www.genome.gov/about-genomics/policy-issues/Synthetic-Biology

* National Human Genome Research Institute (NIH). (2021, 7 de marzo). Genetic engineering. https://www.genome.gov/genetics-glossary/Genetic-Engineering

* Needpix. (s.f.a). Isolated Transparent Plan Free Photo. https://www.needpix.com/ photo/668902/isolated-transparent-plan-engine-car-internal-combustionengines-piston-straps

* Needpix. (s.f.b). Genetic Science Dna Free Photo. https://www.needpix.com/ photo/1112183/genetic-science-dna

* Normile, D. (2019, 30 de diciembre). Chinese scientist who produced genetically altered babies sentenced to 3 years in jail. sciencemag.org. https://www.sciencemag. org/news/2019/12/chinese-scientist-who-produced-genetically-altered-babiessentenced-3-years-jail

* Omaña-Covarrubias, A., Acosta Meneses, M., Moya-Escalera, A. y López-Pontigo, L. (2021). Bioethics and covid-19. Mexican Bioethics Review ICSA 2(4), 29-35. https:// doi.org/10.29057/mbr.v2i4.6299

* Ribeiro, B. y Shapira, P. (2020, febrero). Private and public values of innovation: A patent analysis of synthetic biology. Research Policy, 49(1), 103875. https://doi. org/10.1016/j.respol.2019.103875 
* Shapira, P., Kwon, S. y Youtie, J. (2017). Tracking the emergence of synthetic biology. Scientometrics, 112, 1439-1469. https://doi.org/10.1007/s11192-017-2452-5

* Tan, X., Letendre, J. H., Collins, J. J., y Wong, W. W. (2021). Synthetic biology in the clinic: engineering vaccines, diagnostics, and therapeutics. Cell, 184(4), 881-898. https://doi.org/10.1016/j.cell.2021.01.017

Thadius856 y Parutakupiu. (2008, 4 de enero). Weightlifting pictogram. https:// es.m.wikipedia.org/wiki/Archivo:Weightlifting_pictogram.svg

* VoA - Iris Tong. (2018, 28 de noviembre). [Jiankui He at Second International Summit on Human Genome Editing] [fotografía]. https://commons.wikimedia. org/wiki/File:He_Jiankui_at_Second_International_Summit_on_Human_Genome_ Editing_(cropped).jpg

\section{Cómo CITAR ESTE ARTículo}

* Ruíz Amores, Gerardo. (2021, mayo-junio). Conversando de biología sintética en el gimnasio. Revista Digital Universitaria (RDU), 22(3). http://doi.org/10.22201/ cuaieed.16076079e.2021.22.3.9 